\title{
Association of thrombocytopenia with preeclampsia in a sample of women during labor
}

\section{Dlvin Sartip M. Salih ${ }^{1 *} \quad$ Shahla Karim Alalaf ${ }^{2}$}

\section{Abstract}

Background and objective: Thrombocytopenia (platelet count $<150 \times 10^{9} / \mathrm{L}$ ) is considered the second leading responsible factor in blood disorders in pregnancy after anemia. Substantial thrombocytopenia has been shown to associate with medical conditions. The present study aimed to compare the levels of platelets during labor between the patients diagnosed with preeclampsia and their age-matched healthy subjects.

Methods: In this case-control study, the thrombocytopenia was compared between 55 patients diagnosed with preeclampsia and 59 age-matched healthy controls. In this study, the thrombocytopenia was categorized as follows; normal $\left(150-400 \times 10^{9} / \mathrm{L}\right)$, mild $\left(100-149 \times 10^{9} / \mathrm{L}\right)$, moderate $\left(50-99 \times 10^{9} / \mathrm{L}\right)$, and severe $\left(<50 \times 10^{9} / \mathrm{L}\right)$.

Results: The study showed that the cases and controls were comparable in general information. The number of platelets was significantly lower in patients with preeclampsia (73.58 \pm 26.05$)$ compared to the controls $(262.05 \pm 81.01$; and the $P<0.0001)$. The serum bilirubin $(P<0.0001)$ and the serum creatinine $(P=0.002)$ were substantially lower in the cases compared to the controls in contrast with urine protein $(P<0.0001)$. The patients with preeclampsia were more likely to undergo an emergency cesarean section $(65.5 \%$ vs. $11.9 \%)$, to have antepartum hemorrhage complications $(67.3 \%$ vs. $18.6 \%)$, to get any kind of hypertensive disorders in pregnancy, and to admit the newborns to neonatal intensive care unit $(60.0 \%$ vs. $35.6 \%)$.

Conclusion: The present study showed that the preeclamptic patients had lower platelet count compared to non-pre-eclamptic. In addition, they were more likely to have more obstetrical complications.

Keywords: Thrombocytopenia; Preeclampsia; Hypertensive disorders in pregnancy.

\section{Introduction}

Thrombocytopenia is considered to be the second leading responsible factor in blood disorders in pregnancy after anemia. The incidence of gestational thrombocytopenia is $7-10 \%$ of all pregnancies. The severe thrombocytopenia can impose serious maternal-fetal consequences that need monitoring and proper medical management. Thrombocytopenia is a leading cause of maternal mortality and morbidity worldwide. The evidence reports that women who have thrombocytopenia die due to many complications during and following pregnancy and childbirth like severe bleeding, infections (usually after childbirth), preeclampsia and eclampsia, delivery complications, and unsafe abortion. The majority of these complications are preventable or treatable and may exist before pregnancy and worsen during it. The mentioned complications are responsible for $75 \%$ of all maternal mortality. ${ }^{1}$ Preeclampsia, a hypertensive disorder of pregnancy, is estimated to complicate $2 \%-8 \%$ of pregnancies and remains a principal cause of maternal and fetal morbidity and mortality. Preeclampsia may present at any

${ }^{1}$ Department of Obstetrics and Gynecology, Maternity Teaching Hospital, Erbil, Iraq.

${ }^{2}$ Department of Obstetrics and Gynecology, College of Medicine, Hawler Medical University, Erbil, Iraq.

* Correspondence: drdlveens@gmail.com 
gestation but is more commonly encountered in the third trimester. ${ }^{2}$ During Pre-eclampsia, there is a definite exaggeration of the hypercoagulable state. Of the most common hematological abnormalities during pregnancy is thrombocytopenia. $^{3}$ There are different frequencies, and the intensity of maternal thrombocytopenia depends on the disease process intensity and preeclampsia syndrome duration. According to published articles, the lower level of platelet count in pregnant women has been reported compared to non-pregnant women. Besides, a very high significant association has been found between the degrees of thrombocytopenia with the severity of the preeclampsia. While others did not determine thrombocytopenia as the risk factor for preeclampsia. ${ }^{4}$ Preeclampsia usually happened in the third trimester. ${ }^{5}$ Close to $50 \%$ of the patients with preeclampsia develop thrombocytopenia. Therefore, these patients may present other clinical manifestations. The published studies have reported that there is a very high association between the thrombocytopenia degree with the severity of preeclampsia. ${ }^{6-8}$ The aim of the present study was to compare the levels of platelets during labor between the patients diagnosed with preeclampsia and the women in labor having no preeclampsia.

\section{Methods \\ Study Design and Sampling}

In the present case-control study, the pregnant patients attending the outpatient clinic of a tertiary referral hospital were consecutively screened for eligibility criteria. The patients diagnosed with preeclampsia (PE) were assigned in the case groups $(n=55)$ and their age-matched having no preeclampsia pregnant subjects in the non-PE group $(n=59)$. In this regard, the levels of platelets were compared between the patients diagnosed with preeclampsia and the women in labor having no preeclampsia. The patients were recruited from the outpatient clinic of Erbil
Maternity Hospital between September and November 2018. Ethical approval was obtained from the parents of the patients aged 16 years and less.

\section{Inclusion and Exclusion Criteria}

All the pregnant patients who admitted the maternity hospital to the delivery room and diagnosed with preeclampsia or not, without age restriction or sociodemographic aspects, were eligible for this study. The following persons were excluded from the study: pre-existing renal disease, diabetes, pre-existing endocrine disorders, immune thrombocytopenia purpura (ITP), thrombotic thrombocytopenic purpura (TTP), antiphospholipid antibody (APLA), systemic lupus erythematosus (SLE), patients on medications which are known to cause thrombocytopenia, patients with current chronic hypertension and hematological disorders, and the patients with preeclampsia with normal platelet levels (4 cases).

\section{Diagnostic and Measurement Criteria}

The information was collected from the study were divided into three categories. The first category was general information, and socio-demographic characteristics included age (year), no employee (housewife and student), population (indigenous and immigrant), previous pre-existing hypertension, smoking (categorized as yes or no), systolic blood pressure (SBP: $\mathrm{mmHg}$ ), diastolic blood pressure (DBP: $\mathrm{mmHg}$ ), weight $(\mathrm{Kg})$ and height $(\mathrm{cm})$. The biochemical parameters were collected in the second category, including platelet count, urine protein, blood urea, serum creatinine, GPT, GOT, ALP, and serum bilirubin. The outcomes after delivery and pregnancy consequences were recorded in the third category, including delivery modes (spontaneous vaginal delivery, induction, elective cesarean section, and emergency cesarean section); complications (PPH, $\mathrm{APH}$, and no-complications); hypertension (normal hypertension, mild hypertension, moderate hypertension, and severe 
hypertension); pregnancy outcomes (alive, stillbirth, intrauterine growth restriction, and anomalies); baby weight (kg); NICU admission (yes and no), and NICU admission duration. In this study, the thrombocytopenia was categorized as follows; normal $\left(150-400 \times 10^{9} / \mathrm{L}\right)$; mild $\left(100-149 \times 10^{9} / \mathrm{L}\right) ;$ moderate $\left(50-99 \times 10^{9} /\right.$ L); and severe $\left(<50 \times 10^{9} / \mathrm{L}\right){ }^{9}$ The blood pressure was categorized as normal $(<140 /$ $90 \mathrm{mmHg}$ ); mild (140-149/ 90-99 mmHg); moderate (150-159/ 100-109 $\mathrm{mmHg}$ ); and severe $(\geq 160 / \geq 110)$. The diagnosis of preeclampsia was established according to the following criteria; Systolic blood pressure $140 \mathrm{~mm} \mathrm{Hg}$ or $90 \mathrm{~mm} \mathrm{Hg}$ diastolic that occurs at 20 weeks gestation in a woman with previously normal blood pressure plus proteinuria which defined as urinary excretion $0.3 \mathrm{~g}$ protein in 24 -h urine specimen. ${ }^{10}$

\section{Statistical Methods}

The numerical and categorical variables of the study were displayed in mean \pm SD and frequency (percentage), respectively. The difference in the prevalence of outcomes between the study groups was examined in Pearson Chi-square tests. The difference of biochemical parameters between cases and controls was recognized in an independent t-test. AP value of less than 0.05 two-sided was used to reject the null hypothesis. The statistical calculations were performed by the statistical package for the social sciences (version 25:00; IBM; USA).

\section{Ethical Considerations}

The ethical approval of the present investigation was obtained from the ethical committee of the Kurdistan Board for Medical Specialties. The consent form was obtained from all patients prior to study participation. The permission was obtained from the parents of the subjects aged 16 years and less.

\section{Results}

The comparison of baseline information of the patients diagnosed with preeclampsia and their age-matched non-preeclampsia controls showed that the study group was comparable in age $(P=0.950)$, population $(P=0.619)$, occupation $(P=0.209)$, and smoking $(P=0.064)$. However, the PE patients had a higher prevalence of past hypertension and currently were hypertensive compared to healthy subjects (SBP: $175.33 \pm 14.44$ vs. $107.59 \pm 10.13$ and DBP: $109.85 \pm 12.54$ vs. $67.10 \pm$ 10.017, $P<0.001)$. In addition, the PE patients had a higher BMl compared to healthy subjects $(28.81 \pm 5.417$ vs. $26.97 \pm$ 3.83, $P<0.0001$ ), as shown in Table 1 . The comparison of biochemical parameters between PE and healthy groups showed that the PE patients had a significantly lower concentration of platelet; $264.64 \pm$ 77.36 vs. $203.85 \pm 66.7110^{9} / \mathrm{L}, P<0.0001$ and serum Bilirubin; $0.82 \pm 0.27$ vs. $0.55 \pm$ $0.15 \mathrm{mg} / \mathrm{DI}, P<0.0001$, respectively and higher levels of urine albumin; $2.24 \pm 0.56$ vs. $1.02 \pm 0.13 \mathrm{mg} / \mathrm{L}, P<0.0001$. The $P E$ and healthy study groups were comparable in blood urea (32.76 \pm 12.36 vs. $29.37 \pm$ $6.51 \mathrm{mg} / \mathrm{DI}, P=0.076)$, GPT (30.27 \pm 43.12 vs. $24.91 \pm 7.24$ IU/L, $P=0.367)$; GOT $(25.13 \pm 12.97$ vs. $25.19 \pm 6.82 \mathrm{IU} / \mathrm{L}, P=$ $0.975)$, and ALP (294.00 \pm 79.38 vs. $291.62 \pm 73.31 \mathrm{IU} / \mathrm{L}, P=0.896)$, as shown in Table 2. The comparison of thrombocytopenia between the study groups showed that most of the patients in the PE group had a moderate level of thrombocytopenia (89.1\%) compared to $1.7 \%$ in the non-PE group. Only a small percentage of the PE group patients had a normal, mild, and severe type of thrombocytopenia (3.6\% for each type). The prevalence of thrombocytopenia between the study groups was significantly different between PE and non-PE arms $(P<0.0001)$. The total thrombocytopenia was $6.1 \%$ in all pregnancies, including $10.9 \%$ in PE and $1.7 \%$ in non-PE groups, as shown in Table 3. 
Association of thrombocytopenia with preeclampsia ......

Zanco J. Med. Sci., Vol. 24, No. (2), August, 2020

https://doi.org/10.15218/zjms.2020.035

Table 1: Comparison of baseline information of preeclampsia patients and healthy subjects.

\begin{tabular}{|c|c|c|c|}
\hline Patients characteristic $(n=114)$ & $\begin{array}{c}\text { Non-PE }(n=59) \\
F(\%)\end{array}$ & $\begin{array}{c}\mathrm{PE}(\mathrm{n}=55) \\
\mathrm{F}(\%)\end{array}$ & $P$ value \\
\hline Age; Range: $15-43$ years & $30.10 \pm 4.32$ & $30.04 \pm 6.66$ & $0.950^{*}$ \\
\hline $\begin{array}{l}\text { Population } \\
\text { Indigenous } \\
\text { Immigrant }\end{array}$ & $\begin{array}{c}56(94.9) \\
3(5.1)\end{array}$ & $\begin{array}{c}54(98.2) \\
1(1.8)\end{array}$ & $0.619^{* *}$ \\
\hline $\begin{array}{l}\text { Occupation } \\
\text { Housewife/ No employee } \\
\text { Student }\end{array}$ & $\begin{array}{c}54(91.5) \\
5(8.5)\end{array}$ & $\begin{array}{c}53(98.1) \\
1(1.9)\end{array}$ & $0.209^{* \star}$ \\
\hline $\begin{array}{l}\text { Preexisting Hypertension } \\
\text { Yes } \\
\text { No }\end{array}$ & $\begin{array}{c}0(0.0) \\
59(100)\end{array}$ & $\begin{array}{l}55(100) \\
0(0.0)\end{array}$ & $<0.0001^{* *}$ \\
\hline $\begin{array}{l}\text { Smoking } \\
\text { Yes } \\
\text { No }\end{array}$ & $\begin{array}{l}15(25.4) \\
44(74.6)\end{array}$ & $\begin{array}{l}23(41.8) \\
32(58.2)\end{array}$ & $0.064^{* *}$ \\
\hline $\begin{array}{l}\text { SBP }(\mathrm{mm} \mathrm{Hg}) \\
\text { DBP }(\mathrm{mm} \mathrm{Hg})\end{array}$ & $\begin{array}{l}107.59 \pm 10.13 \\
67.10 \pm 10.017\end{array}$ & $\begin{array}{l}175.33 \pm 14.44 \\
109.85 \pm 12.54\end{array}$ & $\begin{array}{l}<0.0001^{*} \\
<0.0001^{*}\end{array}$ \\
\hline $\begin{array}{l}\text { BMI } \\
\text { Weight (kg) }\end{array}$ & $\begin{array}{c}26.97 \pm 3.83 \\
173 \pm 9.94\end{array}$ & $\begin{array}{c}28.81 \pm 5.417 \\
169 \pm 14.41\end{array}$ & $\begin{array}{l}0.037^{*} \\
0.186^{*}\end{array}$ \\
\hline
\end{tabular}

*Independent t-test, ${ }^{* *}$ Pearson Chi-Square, and ${ }^{* * *}$ Fishers' Exact tests were performed for statistical analyses.

Frequency (Percentage): $n$ (\%), Mean (Standard Deviation): Mean (SD)

Table 2: Comparison of biochemical indicators between PE patients and healthy individuals.

\begin{tabular}{lccc}
\hline Patients characteristics $(\mathbf{n = 1 1 4})$ & Non-PE $(\mathbf{n = 5 9 )}$ & PE $(\mathbf{n = 5 5})$ & $\boldsymbol{P}$ value * \\
\hline Platelet $\left(10^{9} / \mathrm{L}\right)$ & $264.64 \pm 77.36$ & $203.85 \pm 66.71$ & $<0.0001$ \\
Urine Albumin(mg/dL) & $1.02 \pm 0.13$ & $2.24 \pm 0.56$ & $<0.0001$ \\
Blood Urea $(\mathrm{mg} / \mathrm{dL})$ & $29.37 \pm 6.51$ & $32.76 \pm 12.36$ & 0.076 \\
Serum Creatinine $(\mathrm{mg} / \mathrm{dL})$ & $0.706 \pm 0.24$ & $0.85 \pm 0.24$ & 0.002 \\
GPT (IU/L) & $24.91 \pm 7.24$ & $30.27 \pm 43.12$ & 0.367 \\
GOT (IU/L) & $25.19 \pm 6.82$ & $25.13 \pm 12.97$ & 0.975 \\
Alk. Phosphatase (IU/L) & $291.62 \pm 73.31$ & $294.00 \pm 79.38$ & 0.896 \\
Serum Bilirubin $(\mathrm{mg} / \mathrm{dL})$ & $0.55 \pm 0.15$ & $0.82 \pm 0.27$ & $<0.0001$ \\
\hline
\end{tabular}

*Independent t-test was performed for all statistical analyses.

Table 3: Thrombocytopenia between patients with preeclampsia and non-preeclampsia patients

\begin{tabular}{lccc}
\hline Thrombocytopenia & \multicolumn{2}{c}{ Study Groups } & P value -Fishers' Exact Test \\
& Non-PE & PE & 0.041 \\
\hline Thrombocytopenia & $1(1.7)$ & $6(10.9)$ & \\
Normal & $58(98.3)$ & $49(89.1)$ & \\
Mild & $\mathbf{1}(1.7)$ & $1(1.8)$ & \\
Moderate & $0(0.0)$ & $\mathbf{4}(7.3)$ & \\
Severe & $0(0.0)$ & $1(1.8)$ & \\
\hline
\end{tabular}


The outcomes of pregnancy in both PE and healthy women were present in Table 4. The study found that the patients diagnosed with PE were more likely to undergo emergency cesarean section $(65.5 \%$ vs. $11.9 \%, P<0.0001)$ and have APH complication $(67.3 \%$ vs. $18.6 \%$, $P<0.0001$ ), respectively. The PE patients were more likely to have mild hypertension
$(9.1 \%$ vs. $0.0 \%)$, moderate hypertension $(20.0 \%$ vs. $0.0 \%)$, and severe hypertension (69.1\% vs. $1.7 \%$ ), respectively; $P<0.0001$. In addition, their infants were more likely to be admitted to the NICU $(60.0 \%$ vs. $35.6 \%$, $P=0.009$, respectively. The study did not find a significant difference in pregnancy outcomes $(P=0.310)$ and baby weight $(P=0.765)$ between the study groups.

Table 4: Comparison of outcomes between PE patients and non-PE subjects following delivery.

\begin{tabular}{|c|c|c|c|}
\hline $\begin{array}{l}\text { Patients characteristics } \\
(n=114)\end{array}$ & Non-PE $(n=59)$ & $P E(n=55)$ & $P$ value \\
\hline Delivery Modes & & & $<0.0001^{* *}$ \\
\hline Spontaneous VD & $32(54.2)$ & $10(18.2)$ & \\
\hline Induction & 9 )15.3) & $5(9.1)$ & \\
\hline Elective cesarean section & $11(18.6)$ & $4(7.3)$ & \\
\hline Emergency cesarean section & 7 )11.9) & $36(65.5)$ & \\
\hline Complications & & & $<0.0001^{* * *}$ \\
\hline $\mathrm{PPH}$ & $42(71.2)$ & $17(30.9)$ & \\
\hline $\mathrm{APH}$ & $11(18.6)$ & $37(67.3)$ & \\
\hline No-complication & $6(10.2)$ & $1(1.8)$ & \\
\hline Hypertension & & & $<0.0001^{* * *}$ \\
\hline Normal & $58(98.3)$ & $1(1.8)$ & \\
\hline Mild hypertension & $0(0.0)$ & $5(9.1)$ & \\
\hline Moderate hypertension & $0(0.0)$ & $11(20.0)$ & \\
\hline Severe hypertension & $1(1.7)$ & $38(69.1)$ & \\
\hline Pregnancy outcomes & & & $0.310^{* * *}$ \\
\hline Alive & $55(93.2)$ & $51(92.7)$ & \\
\hline Stillbirth & $2(3.4)$ & $0(0.0)$ & \\
\hline Intrauterine growth restriction & $0(0.0)$ & $2(3.6)$ & \\
\hline Anomalies & $2(3.4)$ & $2(3.6)$ & \\
\hline Baby Weight (Kg). & $2.85 \pm .65$ & $2.82 \pm .45$ & $0.765^{*}$ \\
\hline NICU Admission & & & $0.009^{* *}$ \\
\hline Yes & $21(35.6)$ & $33(60.0)$ & \\
\hline No & $38(64.4)$ & $22(40.0)$ & \\
\hline Admission Duration & $64.68 \pm 33.50$ & $65.33 \pm 32.63$ & $0.943^{*}$ \\
\hline
\end{tabular}

*Independent t-test, ${ }^{* *}$ Pearson Chi-square, and ${ }^{* * *}$ Fisher's exact tests were performed for statistical analysis 


\section{Discussion}

The present investigation showed that the significantly lower platelet counts in the PE patients compared to the controls. In addition, the cases and their infants were more likely to have complications compared to their compartment controls. Platelets are involved in hemostasis. They plug the endothelial damage sites and play a surfacing role for secondary hemostasis through the coagulation pathway. ${ }^{9}$ The platelets are generally decreased during pregnancy, especially in the last trimester. ${ }^{11}$ This reduction reaches $10 \%$ less than the pre-pregnancy level. It is claimed that a combination of dilutional effects and platelet destruction acceleration within the placenta has a role in this mechanism. Most of the women have a normal range of platelet, but if they start to decrease, it could result in thrombocytopenia. $^{9}$ The majority of the cases diagnosed with thrombocytopenia were moderate in the PE group and mild in this study's non-PE groups; $7.3 \%$ and $1.7 \%$, respectively). The literature suggests that most cases are mild, with no substantial effects for the mother and her fetus. It can be life-threatening for both mother and baby when it is a part of a complex clinical disorder. It must be considered that the cases of PE in this region could have a critical clinical situation owing to the severity of thrombocytopenia. However, the impact of pregnancy on this disorder, and of this disorder on the pregnancy must be considered in this situation. $^{9}$ The rate of thrombocytopenia reported in this study agrees with the literature $(6.1 \%)$ because thrombocytopenia affects between 6 and $10 \%$ of all pregnant women. ${ }^{3}$ Jalal and Thanoon ${ }^{12,13}$ reported $8.6 \%$ of thrombocytopenia among 600 pregnant women in their third trimester in Kirkuk, Iraq. Another study conducted in Erbil city found that $8 \%$ of all 150 pregnant women recruited in the study were diagnosed with thrombocytopenia. The peak incidence was determined during the third trimester.
They found that gestational thrombocytopenia as the main cause $(73.8 \%)$ followed by hypertensive disorders (23\%), and immune thrombocytopenic purpura $(4 \%)$. They did not find any maternal and fetal complications in their study. In agreement with the present study, the majority of their cases were mild in thrombocytopenia. ${ }^{14}$ The strong point of this study must be traced in filling the gap of evidence in this region. However, the study was not exempt from the limitations. The present study's findings should be analyzed in light of study design and subjects because the case-control study may not always reflect the causal pathway. Also, the patients have selected from one setting to make a difficulty for us to generalize the results to other settings across the country. The patients diagnosed with preeclampsia prior to delivery must be given the special medical care because they are at the significant risk of complications compared to the matched controls, particularly those women with other medical conditions. ${ }^{15}$

\section{Conclusion}

The present study suggests that preeclampsia patients have a higher level of thrombocytopenia than non-preeclamptic subjects. In addition, these patients are more likely to have severe pregnancy outcomes, undergo an emergency cesarean section, and admit their infants to the NICU.

\section{Competing interests}

The authors declare no competing interests.

\section{References}

1. Say L, Chou D, Gemmill A, Tunçalp Ö, Moller A-B, Daniels J, et al. Global causes of maternal death: a WHO systematic analysis. The Lancet Global Health 2014; 2(6):e323-33.

2. English FA, Kenny LC, McCarthy FP. Risk factors and effective management of preeclampsia. Integr Blood Press Control 2015; 8:7.

3. McCrae KR. Thrombocytopenia in pregnancy. ASH Annual Meeting 2010; 2010(1):397-402. 
4. Heilmann L, Rath W, Pollow K. Hemostatic abnormalities in patients with severe preeclampsia. CATH 2007; 13(3):285-91.

5. Stavrou E, McCrae KR. Immune thrombocytopenia in pregnancy. Hematology/ Oncology Clinics 2009; 23(6):1299-316.

6. Asrie F, Enawgaw B, Getaneh Z. Prevalence of thrombocytopenia among pregnant women attending antenatal care service at Gondar University Teaching Hospital in 2014, northwest Ethiopia. J Blood Med 2017; 8:61.

7. Donimath KV, Sambrani AM, Rathod PM. A study on association of thrombocytopenia with pregnancy induced hypertension. IJRCOG 2017; 5(3):808-12.

8. Wang $\mathrm{X}, \mathrm{Xu} \mathrm{Y}$, Luo $\mathrm{W}$, Feng $\mathrm{H}$, Luo $\mathrm{Y}$, Wang $Y$, et al. Thrombocytopenia in pregnancy with different diagnoses: Differential clinical features, treatments, and outcomes. Medicine 2017; 96(29):e7561.

9. Myers B. Thrombocytopenia in pregnancy. TOG 2009; 11(3):177-83.

10. Sibai BM, Committee $\mathrm{P}$, Medicine SfM-F. Evaluation and management of severe preeclampsia before 34 weeks' gestation. AJOG 2011; 205(3):191-8.

11. Boehlen F, Hohlfeld P, Extermann P, Perneger TV, De Moerloose P. Platelet count at term pregnancy: A reappraisal of the threshold. Obstet Gynecol 2000; 95(1):29-33.

12. Jalal SD, Thanoon AM. Thrombocytopenia in Iraqi pregnant women. J Fac Med 2011; 53(2):171-4.

13. Perepu U, Rosenstein L. Maternal thrombocytopenia in pregnancy. POG 2013; 3(1):1-15.

14. Shamoon RP, Muhammed NS, Jaff MS. Prevalence and etiological classification of thrombocytopenia among a group of pregnant women in Erbil City, Iraq. Turk J Hematol 2009; 26(23):123-8.

15. Levy JA, Murphy LD. Thrombocytopenia in pregnancy. JABFM 2002; 15(4):290-7. 